\title{
Failure Analysis of the Multi-Level Series Rotary Seal Device under High-Pressure Water
}

\author{
Zenghui Liu ${ }^{1,2}$ - Changlong Du1, ${ }^{1}$ - Songyong Liu ${ }^{1}-$ Hongxiang Jiang ${ }^{1}$ \\ ${ }^{1}$ China University of Mining \& Technology, School of Mechatronic Engineering, China \\ 2 Monash University, Department of Civil Engineering, Australia
}

High-pressure water jets are used to assist roadheaders in breaking hard rock. The failure life of the high-pressure rotary seal (HPRS) is significant, due to how it affects the safety and efficiency of the roadheader. Here we investigate the mechanical behaviour of the HPRS with a series of experiments. Single-level rotary seal device based studies were conducted to investigate the effect of seal forms, materials, operating pressure and spindle speed on friction torque and leakage. The best seal form from the three kinds of forms was chosen to test the failure life of the multi-level series rotary seal device and the relationships between the operating pressure, spindle speed, temperature, leakage and failure life were analysed. The failure life of rotary seals from Levels 1 to 4 was observed to be 15, 11, 5, and 4 days respectively. The increase in temperature of Levels 1 and 2 was perceived to be slow at the beginning phase of the test, while it rose sharply until the failure occurred, whereas in the case of Levels 3 and 4 it was instantaneous.

Keywords: failure analysis, rotary seal, mechanical testing, wear, high pressure

Highlights

- The material and seal forms have significance effect on the friction torque.

- $\quad$ The leakage increases with operating pressure and lower spindle speed.

- Failure life of seal from Levels 1 to 4 is 15, 11, 5 and 4 days, respectively.

- The rate of increase in temperature of Levels 1 and 2 is slow in the beginning followed by a sharp rise.

\section{INTRODUCTION}

With the increase in energy demand, the demand for coal remains high throughout the world. Coal accounts for around $70 \%$ of the energy consumed in China, while the total demand for coal is increasing every year. Roadway excavation is the first step in coal mining, and the wear of the cutting mechanism of the roadheader is crucial in this process, which has a considerable impact on the reliability of the equipment. The wide use of water jets in mining, petroleum drilling, machine, civil construction, gas drainage, and cleaning operations has suggested that the cutting force and the wear of cutter, as well as the dust produced in the cutting process, can be reduced with the assistance of water jets [1]. As shown in Fig. 1 , since the motors drive the cutting head and shaft through the transmission while the rotary seal device remains fixed to the gearbox, the seal between the water jet and the drive shaft is a rotary seal during the cutting process. In order to break rock effectively, the water jet is usually at high pressure [2], which increases the difficulty of the rotary seal. Therefore, the sealing performance and failure life of the high-pressure rotary seal (HPRS) have a significant influence on the rock breaking process of the roadheader.

There has been significant research by many researcher and engineers on rotary seals and high- pressure seals. For example, to obtain an effective tool for predicting the leakage and the dynamic response of honeycomb seals, Saba et al. [3] reviewed the bulk flow model and explored its sensitivity to different hypotheses. Plath et al. [4] conducted an experimental study of rotary shaft lip-type seals and surveyed the torque variation with rotary speed and temperature. Stolarski and Tucker [5] obtained the variations in squeeze force and operating pressure across O-rings, followed by an analysis of the relationship between frictional force and gauge pressure in various types of O-ring seals at the commencement of the linear motion of the shaft.

Bistrazy et al. [6] conducted endurance and friction characteristic tests on U-ring seals and reported the critical operating seal parameters under different design and working conditions by measuring the friction force and leakage endurance curves. They also analysed the effect of increased operating pressures on the friction force increment under reciprocating motion. Kim and Shim [7] used the Mooney-Rivlin model to study the contact force and thermal behaviour of radial lip seals as a function of the contact interface. Wang and Liu [8] explored the creep behaviour and sealing performance of the inner casing of a supercritical steam turbine. The stiffness and damping coefficients of the oil seals were evaluated by Baheti and Kirk [9] using the perturbation 
technique; eigenvalue analysis was performed to study the dynamic stability of the compressor rotor. While establishing the numerical model of the O-ring used in the compensatory configuration of the mechanical seal, Li et al. [10] also obtained the Von-Mises stress and contact stress of the O-ring. These researchers performed experiments on a high-frequency failure machine and a water-lubricated O-ring tester to obtain the results of friction force.

Liao et al. [11] investigated the elastohydrodynamic lubrication characteristics of the O-ring seal using friction and wear testers, both numerically and experimentally. In their study, the efficiency of the fluid-solid interaction derived from experimental results reinforced their numerical fluidsolid interaction model constructed by analysing the fluid lubrication, contact mechanics, asperity contact and elastic deformation. Yang and Salant [12] and [13] demonstrated the usefulness of simulation in the selection of reciprocating seals. The numerical predictions in the study disclosed that the performance of the O-ring is inferior to that of a U-cup seal. Wiznera et al. [14] performed investigations based on 2D measurements of five equally-distributed areas of the ring to prove the effectiveness of the seal. Yamabe et al. [15] performed pressure cycle tests at hydrogen pressures ranging from $10 \mathrm{MPa}$ to $70 \mathrm{MPa}$ and ambient temperatures ranging from $30{ }^{\circ} \mathrm{C}$ to 100 ${ }^{\circ} \mathrm{C}$ to analyse the fracture behaviour of O-rings. The effects of O-ring seals on the effective area of the oiloperated pressure balance were investigated by Woo et al. [16] using two-piston cylinder assemblies in the pressure range of $100 \mathrm{MPa}$ to $300 \mathrm{MPa}$. Nishimura [17] conducted high-pressure (up to $70 \mathrm{MPa}$ ) hydrogen pressurisation-decompression cycle tests on O-rings to investigate the fracture behaviour of O-rings.
The above studies have applied various experiments and simulations, resulting in fruitful achievements as references for the present work. In the previous studies discussed above, information about friction torque and force with rotary speed, temperature and operating pressure, and the elastohydrodynamic lubrication in various types of seals were the focus., the failure life test of the rotary seal under high pressure, especially the multi-level series rotary seal has received little attention to date.

Therefore, the experimental analysis of HPRS mechanical behaviour is investigated in this paper, which reports the results of experiments on singlelevel rotary seal devices to investigate the effect of seal forms, materials, operating pressure and spindle speed on friction torque and leakage. The best seal form was determined and chosen to further test the failure life of the multi-level series rotary seal device, and the relationships between the operating pressure, spindle speed, temperature, leakage and failure life were analysed.

\section{EXPERIMENTAL}

To test the failure life of the rotary seal, an experimental set-up for HPRS was designed, and experiments were conducted. Fig. 2 shows a detailed description of the experimental set-up. As the power producer, the motor is controlled by the PLC program [18]. To ensure a high axiality, the bearing seat has a cylindrical surface that matches well the shell of the rotary seal device and is bolted with the shell by six bolts. The torque/speed transducer is installed between the motor and the bearing seat, and two couplings are used to combine the above three facilities. The water in the reservoir is pumped and transformed to highpressure water, and then the pressurized water is

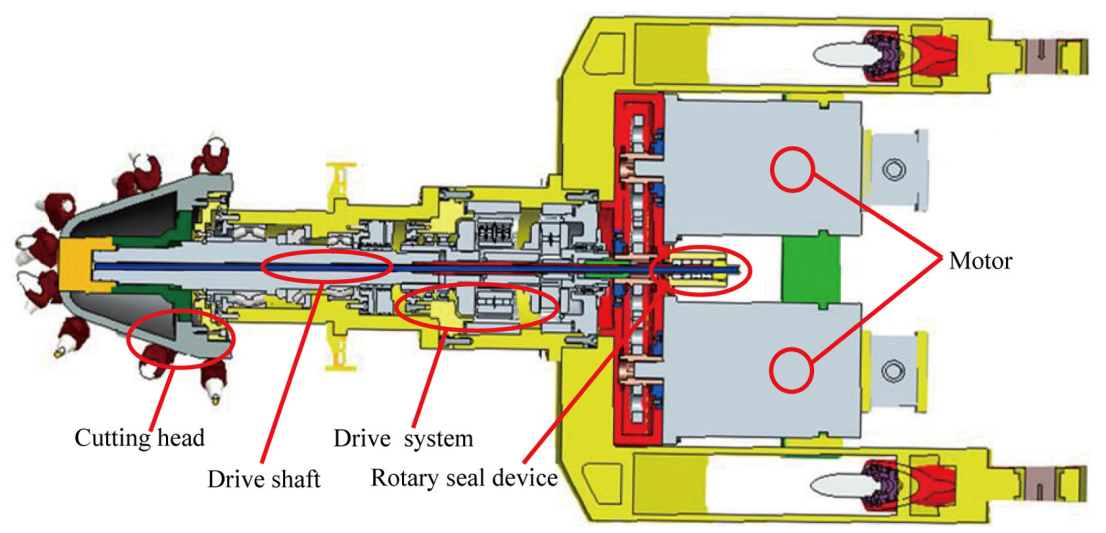

Fig. 1. Structure of roadheader cutting unit with rotary seal device 


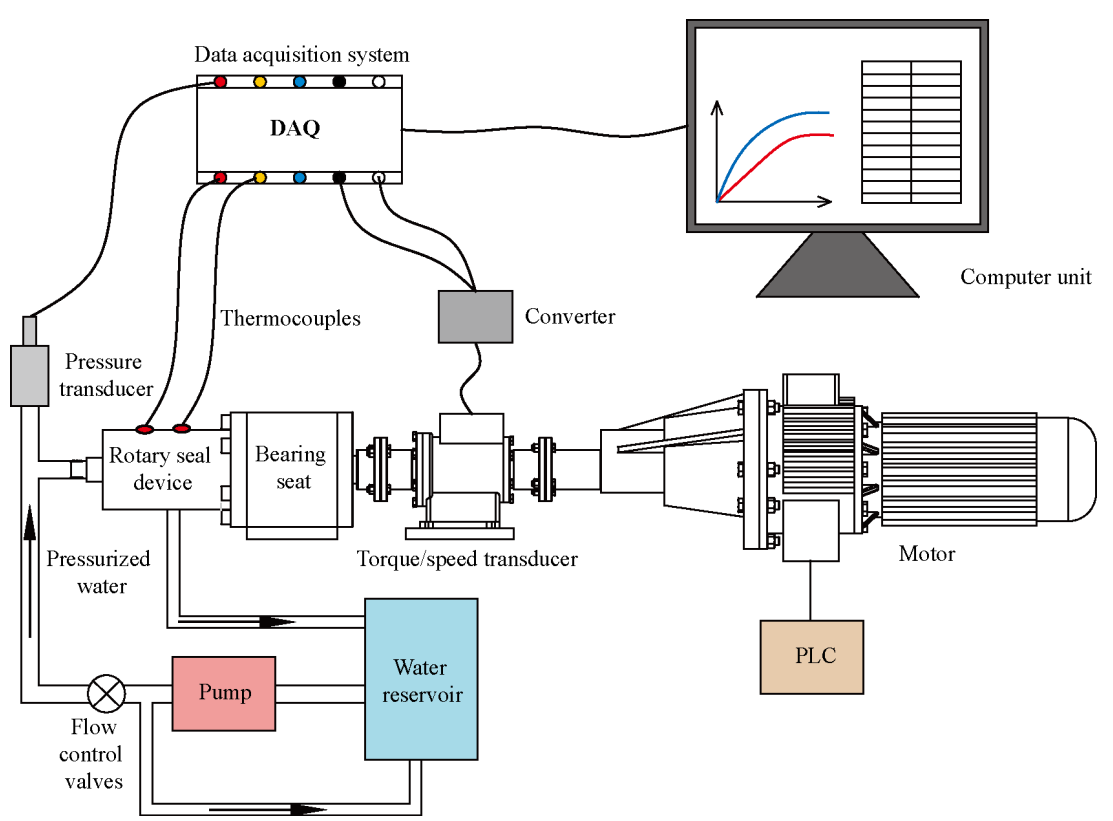

Fig. 2. Schematic of HPRS set-up

streamed through the flow control valves to the inlet of the rotary seal device and the pressure transducer, and the superfluous pressurized water is directed back to the reservoir.

A USB data acquisition system (DAQ), consisting of numerous transducers, a DAQ card, and a computer unit, is used to monitor a range of parameters during the experimental process. The DAQ card includes sixteen independent channels and monitors. In the experiments, the excitation voltage measurement range is from $-10 \mathrm{~V}$ to $10 \mathrm{~V}$ and the data sampling rate is adjustable up to $250,000 \mathrm{~Hz}$. The pressure transducer JNBP-30 processes the water pressure signal to the voltage signal and sends it to the DAQ card directly. The thermocouple placed in the rotary seal device monitors the temperature of the seal rings and sends it to the DAQ card. Because the output signals of the torque/speed transducer are pulse signals, a converter is connected to the torque/speed transducer to convert the pulse signals to the voltage signals and send them to the DAQ card. Then, the analysable digital data is sent to the computer unit and displayed there.

The rotary seal device is the key unit of the whole set-up. According to the installation position and the size of rotary seal device shown in Fig. 1, the multiplelevel rotary seal is designed to be of four levels, as shown in Fig. 3.

Based on the relative motion between the seal and the mechanical parts, there are two kinds of seal: static and dynamic. The high-pressure water flows from the inlet in the joint, then through the flow channels in the joint and the shaft, and finally to the outlet in the shell. The joint is bolted to-the shell, and since there is no relative motion among the joint, shell and seal chambers, the common O-rings were adopted as the static seal. While the shaft rotates and the seal chambers are static, the dynamic seal is implemented from the rotary seal rings. With the function of the static seal ring and the rotary seal ring, the highpressure water flows to the outlet successfully. Because the dynamic seal can be broken more easily than the static seal, and the higher the water pressure, the worse the sealing effect may be, our work mainly focused on the mechanical behaviour and failure life of the HPRS [19]. The diameter of the shaft is $25 \mathrm{~mm}$, and for monitoring the temperatures of the rotary seal rings, thermocouples are placed in holes 2 $\mathrm{mm}$ from the rotary seal rings and shaft. During the experimental process, all the leakage holes were open at first, and once the leakage rate of the first leakage hole rose to the prescribed value, the first leakage hole was plugged by the screw plug, allowing the highpressure water to flow to the second-level rotary seal ring, and the leakage ran out from the second leakage hole. By analogy, the failure of the whole rotary seal unit followed when the leakage of the fourth leakage hole rose to the prescribed value.

During the experimental process, the motor was started first, and the speed was adjusted to the 


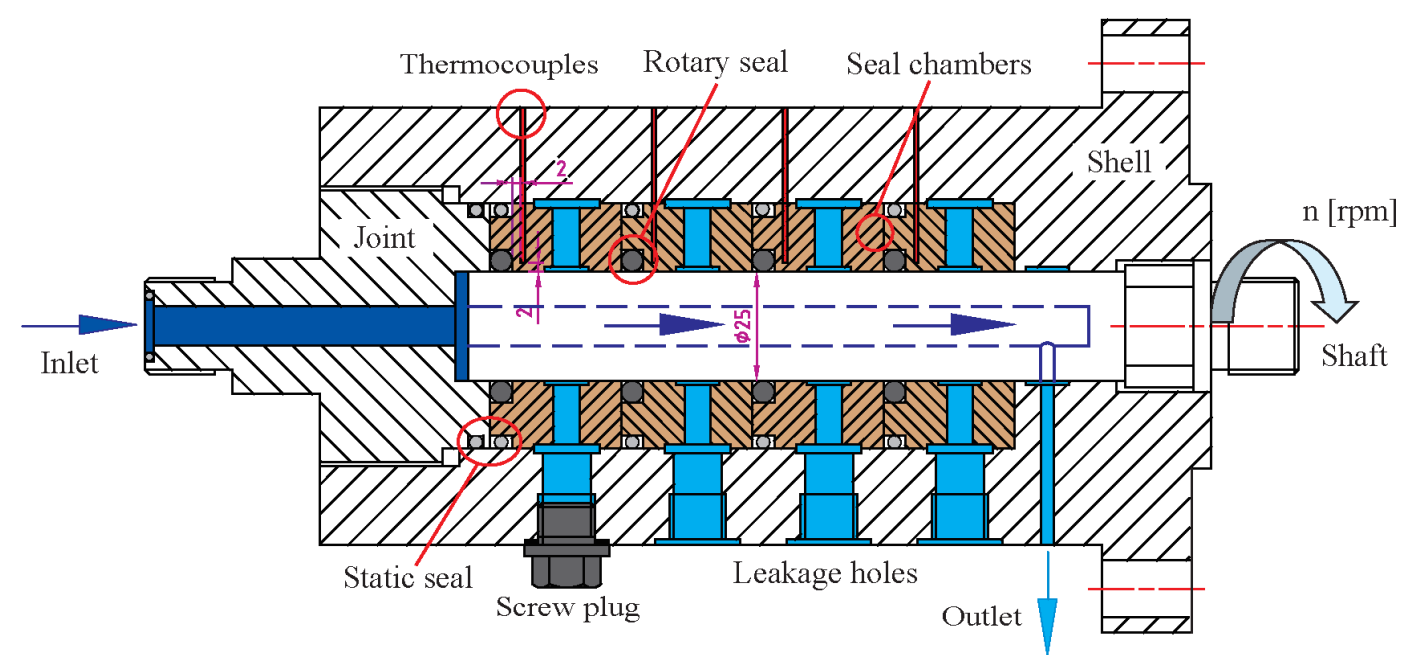

Fig. 3. Schematic of the HPRS device

required value. After the motor running smoothly, the pump was started, and the pressure is adjusted to reach the required value. Then the experimental data were collected and stored in the computer. After the completion of a group of tests, the speed of the motor and the pressure of water were adjusted slowly, and when the motor and pump were once again running smoothly, a new group of tests was started. When the tests were finished, the pressure of pump decreases firstly, afterwards the pump and the motor were turned off.

\section{RESULTS}

\subsection{Analysis of the Single-Level Rotary Seal Device}

In order to test the failure life of the multi-level series rotary seal device efficiently, the mechanical behaviour of the single-level rotary seal was analysed first, so that the best rotary seal form could be chosen for the failure life test. During the process of the single-level rotary seal test, the seal chambers of Levels 2, 3 and 4 were installed with the shell without rotary seals to test the effect of a series of parameters on the HPRS performance.

For the HPRS, the most common forms are the O-ring seal and the tooth slip ring combined seal. Fig. 4 represents the cross-section geometries of the three seals. Fig. 4a shows the common nitrile butadiene rubber (NBR) O-ring seal, Fig. 4b is the common NBR O-ring coated with polytetrafluoroethylene (PTFE), and Fig. 4c is the combined seal, which consists of a NBR O-ring and a PTFE tooth slip ring. In this study, the internal diameter of the three seals was $25 \mathrm{~mm}$, and the cross-section diameter of the three O-rings was $3.53 \mathrm{~mm}$. To study the effect of seal form and material on friction torque, the speed of the motor was set at $50 \mathrm{rpm}$, which is the speed of the roadheader under actual working conditions, and the pressure of the pump was adjusted to $40 \mathrm{MPa}$, which is the highest demand based on the design.

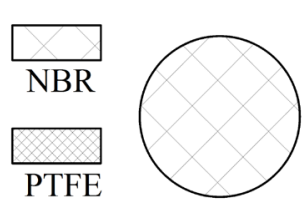

a)

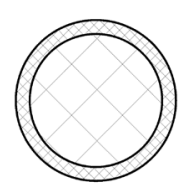

b)

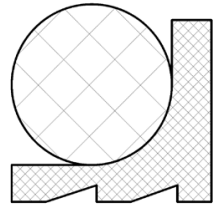

c)
Fig. 4. Cross-section geometries of the three seals: a) common 0-ring seal; b) coated 0-ring seal; c) combined seal

Fig. 5 shows the friction torque curves of different seals under the same conditions. According to the calculations, the mean friction torque of the three seals was $6.31 \mathrm{~N} \cdot \mathrm{m}, 5.68 \mathrm{~N} \cdot \mathrm{m}$ and $5.02 \mathrm{~N} \cdot \mathrm{m}$, respectively. It should be noted that the curves changed periodically, and each cycle length matches well the speed of the shaft, which indicates that the contact pressure of the seals changed with the rotation of the shaft because of the tiny deviation of the coaxial and the uneven deformation of the seals during the squeezing process. Compared with the coated O-ring seal, the amplitude of the common NBR O-ring seal was larger, due to the different material properties of the NBR and the PTFE. The Young's modulus of the NBR was smaller, which resulted in the larger uneven deformation. However, the friction coefficient of the NBR was larger, and the amplitude and the mean 
value of the common NBR O-ring seal were larger. This established that the material has a significant effect on friction torque. A comparison of Figs. 4b and $4 \mathrm{c}$ indicates that the seal form has a small effect on the changing trend of the friction torque, but has a great effect on the mean value of the friction torque. The mean value of the combined seal was smaller than the coated O-ring seal, which demonstrates that the mechanical behaviour of the combined seal works better.

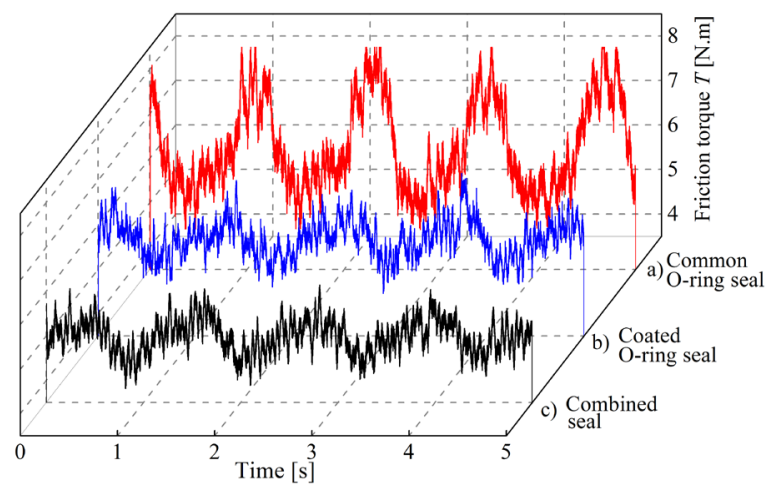

Fig. 5. Friction torque curves of different seals

Depending on the actual working conditions of the roadheader, if the water flows all around the tunnelling working surface will cause great trouble, so it is important to control the leakage rate of the rotary seal. In addition, leakage affects the rock breaking efficiency by reducing the pressure of the water jet. Therefore, the maximum leakage allowed was defined as $50 \mathrm{~mL} / \mathrm{h}$, based on the design of the rotary seal device.

Fig. 6 shows the curves of leakage under different operating pressures, where the solid lines are the three seal types in a static condition, and the dash lines are the three seal types at $50 \mathrm{rpm}$ spindle speed. The leakages of both common O-ring seals and coated O-ring seals increased the operating pressure, while the leakages of the combined seals decreased with the operating pressure. This can be attributed to the different deformations of seals under different operating pressures. As the O-ring in the combined seal had the smaller deformation compared with the O-ring seal, the leakages of combined seals were higher than those of the O-ring seals under $0.5 \mathrm{MPa}$ operating pressure. For the combined seal, the higher the $\Delta P$, the greater the deformation of the O-ring. This could cause the higher contact pressure between the tooth slip ring and the shaft, resulting in smaller leakage. However, for the O-ring seal, the higher $\Delta P$ may cause greater deformation of the O-ring, but the
O-ring could be twisted easily and even overturned when the deformation was great enough, and then the leakage then increased with $\Delta P$. For the common O-ring seal, both the static leakage and dynamic leakage under $40 \mathrm{MPa}$ operating pressure were beyond the allowed maximum leakage of $50 \mathrm{ml} / \mathrm{h}$. Therefore, the common O-ring seal is not suitable for a rotary seal device under high pressure.

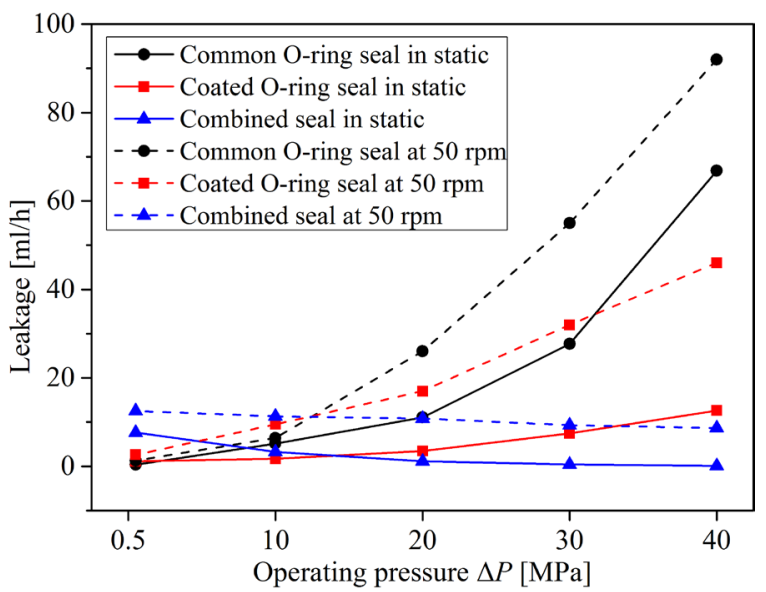

Fig. 6. Effect of operating pressures on leakage

Fig. 7 represents the variations of leakages of the three seal types with different spindle speeds under 40 MPa operating pressure. It shows that the variation trends of the curves are not obvious. The leakages increase speed at lower spindle speed, and then remain almost unchanged with any further increase in speed. The reason is that the faster speed causes the water to be pushed into the contact zone easily, resulting in the easy formation of the lubrication film.

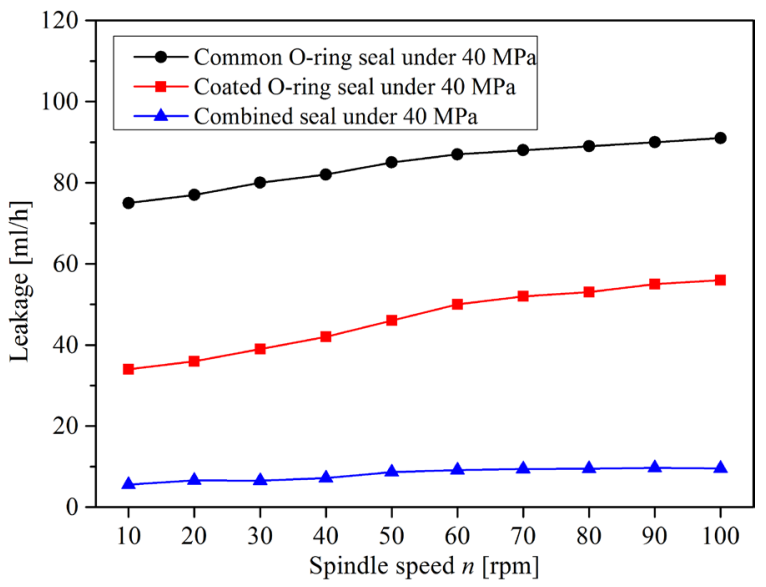

Fig. 7. Effect of spindle speeds on leakage

When the spindle speed reached $70 \mathrm{rpm}$, the lubrication film formed was quite effective, not only 
reducing the wear but also the leakage, as the leakage changed slightly with the higher spindle speed. Moreover, the leakage of the common O-ring seal and coated O-ring seal changed within $75 \mathrm{ml} / \mathrm{h}$ to $90 \mathrm{ml} / \mathrm{h}$ and $35 \mathrm{ml} / \mathrm{h}$ to $60 \mathrm{ml} / \mathrm{h}$, respectively, while the leakage of the combined seal was around $10 \mathrm{ml} / \mathrm{h}$. The leakage of the combined seal was the smallest among the three seal types.

\subsection{Analysis of the Combined Seal in Multi-Level Series Rotary Seal Device}

From above analysis, it is evident that the sealing effect of the combined seal is best, because of its smaller friction torque, greater contact pressure and smaller leakage. As a result, the combined seal was chosen to conduct the failure life test of the multilevel series rotary seal device. The rotary seal test-bed and a schematic of the rotary seal device are shown in Figs. 2 and 3, and the inner structure of the multilevel series rotary seal device is shown in Fig. 8. The rotary seal device-has four levels, the rotary seals were the combined seals, the static seals were the common O-ring seals, the seal chambers were made of brass, and the shaft was made of stainless steel.

According to Lingerkar [18], the operating pressure and the shaft sliding velocity have a great influence on the performance of the rotary seal. Figs. 9 and 10 show the temperatures and leakages of rotary seal level 1 at $50 \mathrm{rpm}$ spindle speed under operating pressures of $10 \mathrm{MPa}, 20 \mathrm{MPa}, 30 \mathrm{MPa}$ and $40 \mathrm{MPa}$. The temperatures were measured by placing thermocouples $2 \mathrm{~mm}$ from the rotary seal rings and shaft, as shown in Fig. 3.

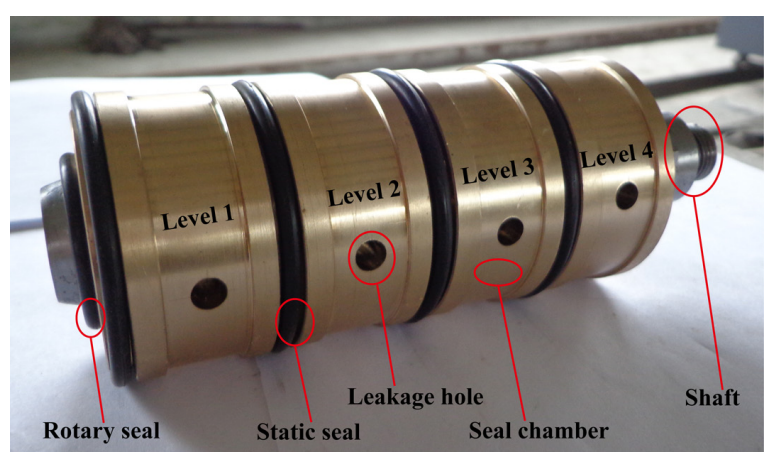

Fig. 8. Inner structure of the multi-level series rotary seal device

Fig. 9 shows that the trends of temperatures under different operating pressures are similar; the temperature increases quickly for the first several hours, and then the rate of increase slows. However, the temperature in all cases remains high under higher operating pressure. For example, after 10 hours of testing, the temperatures under $10 \mathrm{MPa}, 20 \mathrm{MPa}, 30$ $\mathrm{MPa}$ and $40 \mathrm{MPa}$ were $31{ }^{\circ} \mathrm{C}, 34{ }^{\circ} \mathrm{C}, 38{ }^{\circ} \mathrm{C}$ and 43 ${ }^{\circ} \mathrm{C}$, respectively. The reason may be that the higher the $\Delta P$, the greater the contact pressure between the tooth slip ring and the shaft, which in turn results in higher temperatures.

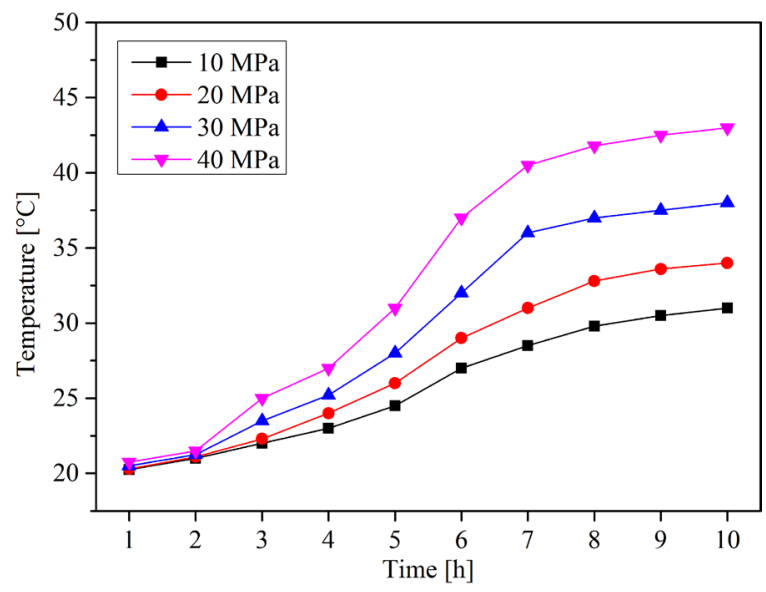

Fig. 9. Temperatures of seals under different operating pressures

Fig. 10 shows that the leakages under each operating pressure remained at steady states within the 10 hours, because the seals were well lubricated and worked well during that period. Meanwhile, the leakages in all cases persisted less for relatively higher operating pressure. The reason may be that the higher the $\Delta \mathrm{P}$, the greater the contact pressure between the tooth slip ring and the shaft, causing less leakage, as shown in Fig. 6.

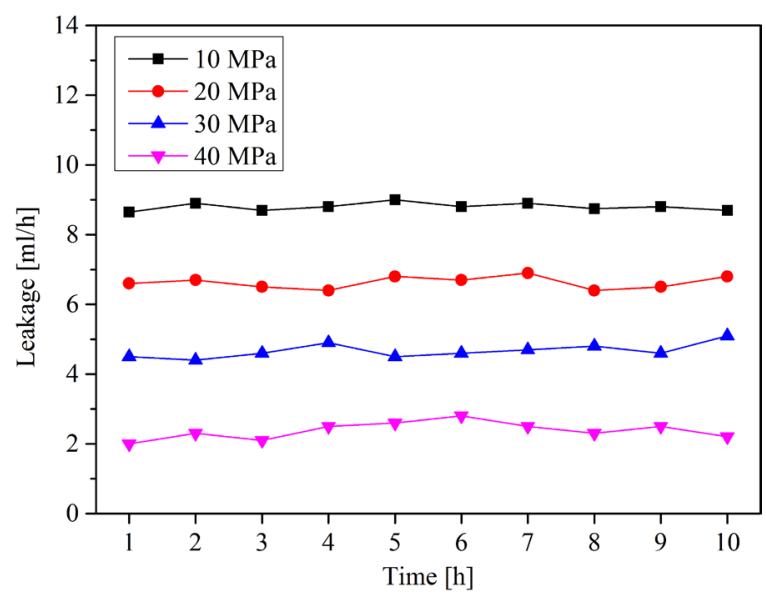

Fig. 10. Leakages of seals under different operating pressures

Fig. 11 presents a series of experimental temperature curves at different spindle speeds under 
the operating pressure of $40 \mathrm{MPa}$. It was observed that the temperature rises sharply at the beginning of the test, and then increases slowly, and some temperature curves at lower spindle speeds gradually tend to reach a steady state with sliding time. Moreover, the temperature in all cases remains higher under relatively higher spindle speeds. For example, after 10 hours of testing, the temperature at $50 \mathrm{rpm}$ was $43{ }^{\circ} \mathrm{C}$, and the temperature increased to $82{ }^{\circ} \mathrm{C}$ when the spindle speed was $100 \mathrm{rpm}$. The reason is that the faster the speed, the more frictional heat at the contact zone is generated, and the higher the temperature remains.

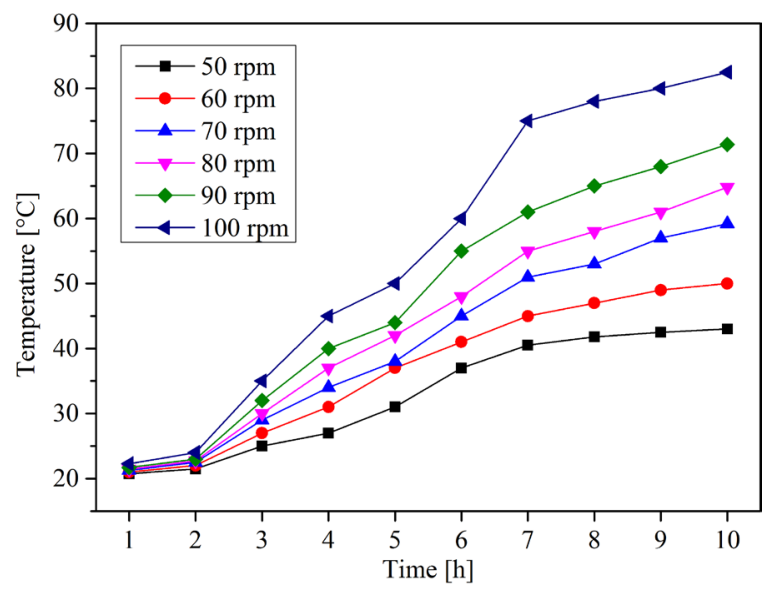

Fig. 11. Temperatures of seals at different spindle speeds

Fig. 12 shows that the leakages at each spindle speed remained at a steady state within the 10 hours, because the seals were well lubricated and working well. Meanwhile, the leakages remained less at relatively lower speeds, but there was little difference in the leakages for the speeds of $70 \mathrm{rpm}$ to $100 \mathrm{rpm}$. The reason is shown in Fig. 6.

Based on the actual working conditions of roadheaders, excavation and support are alternative modes of operation, and as the roadheader is in a shutdown state during the support process, the whole working time of the roadheader is approximately 10 hours a day. Moreover, since comprehensive inspections, maintenance and repairs of roadheaders are commonly conducted once a month, the expected life of a multi-level series rotary seal device is at least 30 days. The rated speed of the roadheader is around $50 \mathrm{rpm}$, but the speed is sometimes set at $100 \mathrm{rpm}$ to break hard rock. Therefore, the spindle speed of the motor was set at $100 \mathrm{rpm}$ during this test, and the motor ran from 8 am to $6 \mathrm{pm}$ every day to make a total of 10 hours a day. The temperature was measured three times at 6 pm every day, and the average values were recorded, and these are shown in Fig. 13. Meanwhile, the leakages were collected from $5 \mathrm{pm}$ to $6 \mathrm{pm}$ every day, and the values are presented in Fig. 14.

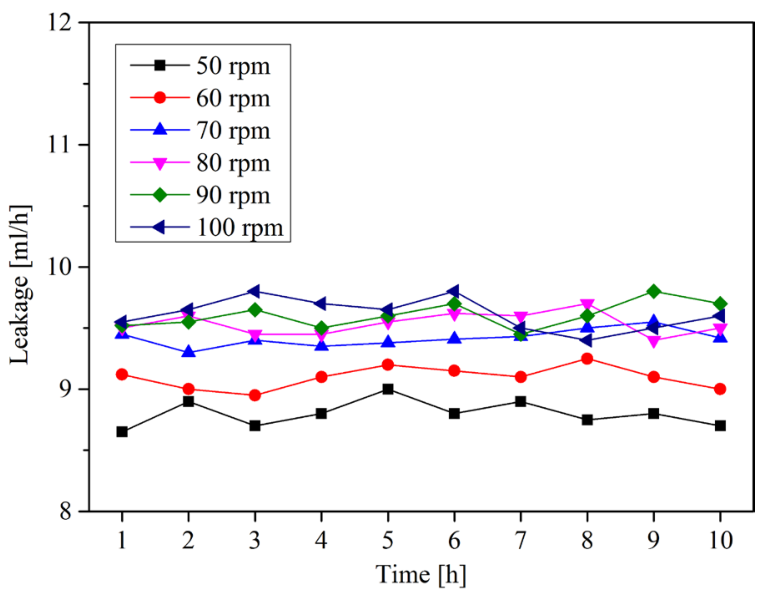

Fig. 12. Leakages of seals at different spindle speeds

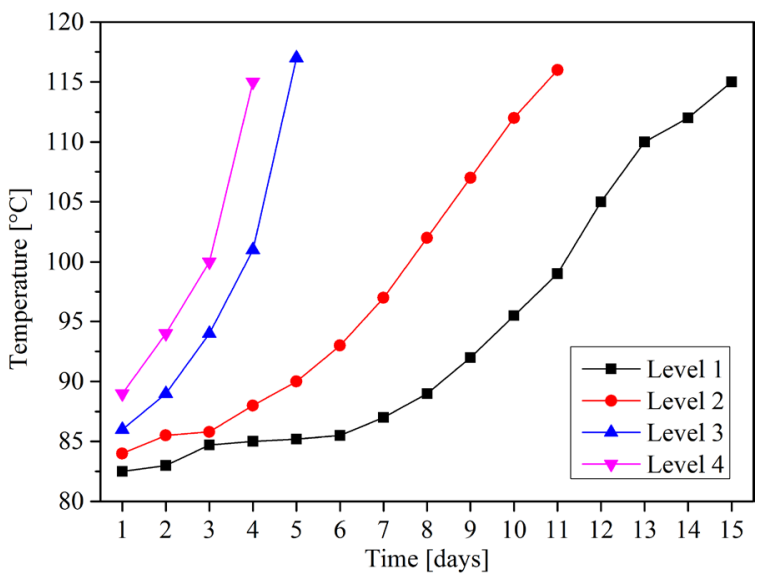

Fig. 13. Failure life and temperature of each level rotary seal

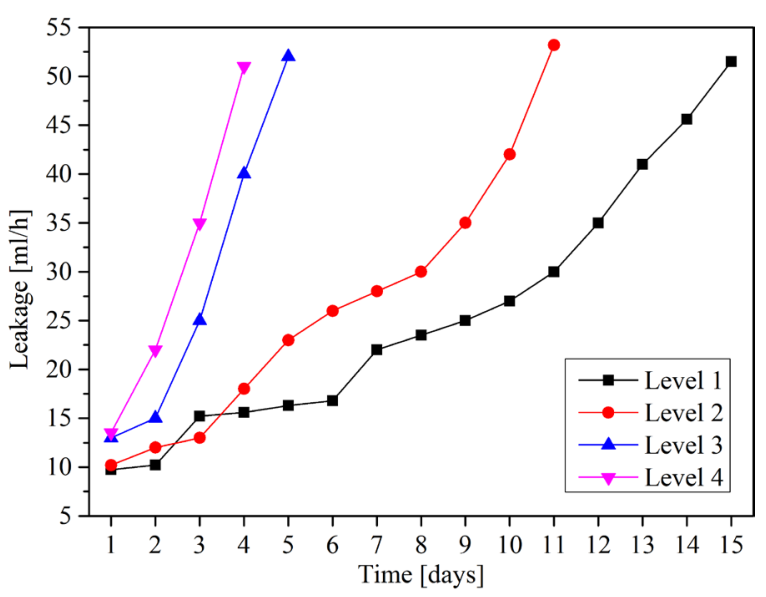

Fig. 14. Failure life and leakage of each level rotary seal 


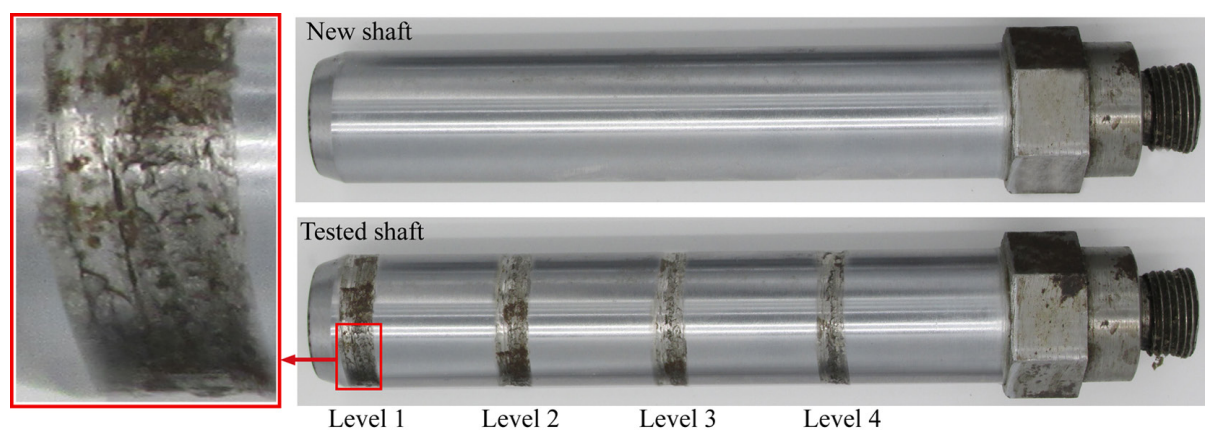

Fig. 15. Comparison of the shaft before and after failure

As shown in Figs. 13 and 14, the failure life of the rotary seal from Level 1 to Level 4 was 15 days, 11 days, 5 days and 4 days, respectively. The temperatures of all levels rise with time, but the temperature of Levels 1 and 2 increase slowly in the beginning phase of the test and then go up sharply until their failure, while the temperature of Levels 3 and 4 rise instantaneously. The trends of the leakage curves are similar to the temperature curves. For Level 1, the seal performance at the interface between the tooth slip ring and the shaft was quite good for the first two days of the test, and then the rotary seal advanced to a stable period during the $3^{\text {rd }}$ to $6^{\text {th }}$ day, which was the best period. The tooth slip ring is usually made of PTFE, and some is generated because of the continuous friction and wear at the interface. Some PTFE dross may be discharged with the leakage, while other such dross may remain at the interface, which will in turn increase the frictional coefficient and frictional heat, and even damage the shaft, generating some metal dross. It is a vicious cycle that the accumulative high frictional heat damages the tooth slip ring and the shaft, while the dross from the damaged tooth slip ring and shaft increase the frictional heat at the interface. Therefore, both the temperature and leakage increased gradually from the $7^{\text {th }}$ day to $15^{\text {th }}$ day when the leakage was beyond $50 \mathrm{ml} / \mathrm{h}$.

According to Fig. 3, once the leakage hole of Level 1 was plugged by the screw plug, the highpressure water could flow to the rotary seal ring of Level 2, and some dross could flow to the interface of the Level 2 directly. Therefore, the curves of Level 2 have no stable period compared with Level 1 , and the failure life is shorter than that of Level 1 . Fig. 14 shows the comparison of the shaft before and after failure. It was observed that the damage at the interface of Level 1 was the most serious, while the damage of level 4 was the slightest. The reason is that the friction at the interface of Level 1 will continue constantly because of the poor thermal conductivity property and the great thermal expansion coefficient of PTFE. Therefore, more PTFE and metal dross from Levels 1 and 2 may flow to the interface of Levels 3 and 4 , and then the temperature and leakage increase sharply as shown in Figs. 14 and 15, which cause the fast failure of the rotary seal.

The whole failure life of the multi-level series rotary seal device was found to be 35 days, well beyond the expected life. Most of the time, the speed of the shaft was around $50 \mathrm{rpm}$, not $100 \mathrm{rpm}$ during the working process. As a result, the actual failure life of the four-level rotary seal device under working conditions would be longer than 35 days, and the extra life can be regarded as safety assurance. However, for the multi-level series rotary seal device, the series is not the best, because the failure life of the later level was too short in comparison with the earlier level. The suggested series for rotary seal devices similar to that described in this paper is three or four levels.

\section{CONCLUSIONS}

In this study, we have successfully employed experimental analyses to investigate the seal performance and failure analysis of the multi-level series rotary seal device. The following conclusions can be drawn.

Experimental analyses of the single-level series rotary seal device indicate that the mechanical behaviour of the combined seal is better than that of the O-ring seal. The leakages of O-ring seals increase with the operating pressure, while the leakages of combined seals decrease with the operating pressure. In addition, the leakage increases with speed at lower spindle speed, and then reaches a value after which it remains almost unchanged with any further increase in speed. 
The combined seal was chosen to conduct failure life test of the multi-level series rotary seal device, and it was found that the failure life of rotary seals from Level 1 to Level 4 is 15 days, 11 days, 5 days and 4 days, respectively. The temperatures of all the levels rise with time, but the temperatures of Levels 1 and 2 increase slowly at the beginning of the test and then rise sharply until their failure, while the temperature of Level 3 and Level 4 rise instantaneously. Furthermore, the trends of the leakage curves are similar to those of the temperature curves.

\section{ACKNOWLEDGEMENTS}

This paper is jointly supported by the Priority Academic Program Development of Jiangsu High Education Institute of China, the National Natural Science Foundation of China (No. 51375478) and the China Postdoctoral Science Foundation funded project (No. 2015M581880).

\section{REFERENCES}

[1] Liu, X., Liu, S., Li, L., Cui, X. (2015). Experiment on conical pick cutting rock material assisted with front and rear water jet. Advances in Materials Science and Engineering, Article ID 506579, DOI:10.1155/2015/506579.

[2] Jiang, H., Du, C., Zheng, K., Liu, S. (2015). Experimental research on the rock fragmentation load of water jet-assisted cutting head. Tehnički vjesnik - Technical Gazzete, vol. 22, no. 5, p. 1277-1285, DOl:10.17559/TV-20141020152601.

[3] Saba, D., Forte, P., Vannini, G. (2014). Review and upgrade of a bulk flow model for the analysis of honeycomb gas seals based on new high-pressure experimental data. Strojniški Vestnik - Journal of Mechanical Engineering, vol. 60, no. 5, p. 321-330, Dol:10.5545/sv-jme.2014.1835.

[4] Plath, S., Mayer, S., Wollesen, V. M. (2016). Friction torque of a rotary shaft lip type seal-a comparison between test results and finite element simulation. Mechanics, vol. 54, no. 4, p. 55-59.

[5] Stolarski, T.A., Tucker, M. (1996). Frictional performance of an 0-ring type seal at the commencement of linear motion. Tribology Letters, vol. 2, no. 4, p. 405-416, D0l:10.1007/ BF00156912.

[6] Bisztray-Balku, S. (1999). Tribology of elastomeric and composite reciprocating hydraulic seals. Periodica Polytechnica. Engineering. Mechanical Engineering, vol. 43, no. 1, p. 63-80.
[7] Kim, C.K., Shim, W.J. (1997). Analysis of contact force and thermal behaviour of lip seals. Tribology International, vol. 30, no. 2, p. 113-119, Dol:10.1016/0301-679X(96)00030-8.

[8] Wang, W., Liu, Y. (2015). Analysis of the sealing performance and creep behavior of the inner casing of a $1000 \mathrm{MW}$ supercritical steam turbine under bolt relaxation. Engineering Failure Analysis, vol. 57, p. 363-376, D0l:10.1016/j. engfailanal.2015.08.012.

[9] Baheti, S.K., Kirk, R.G. (1999). Analysis of high pressure liquid seal ring distortion and stability using finite element methods. Journal of Tribology, vol. 121, no. 4, p. 921-926, DOI:10.1115/1.2834156.

[10] Li, S.X., Cai, J.N., Zhang, Q.X., Jie, L., Gao, J.J. (2010). Performance Analysis of O-ring Used in Compensatory Configuration of Mechanical Seal. Tribology, vol. 30, no. 3, p. 308-314. (in Chinese)

[11] Liao, C., Huang, W., Wang, Y., Suo, S., Liu, Y. (2013). Fluidsolid interaction model for hydraulic reciprocating 0-ring seals. Chinese Journal of Mechanical Engineering, vol. 26, no. 1, p. 85-94, DOI:10.3901/CJME.2013.01.085.

[12] Yang, B., Salant, R.F. (2008). Numerical model of a tandem reciprocating hydraulic rod seal. Journal of Tribology, vol. 130, no. 3, p. 032201, DOl:10.1115/1.2908924.

[13] Yang, B., Salant, R.F. (2011). Elastohydrodynamic lubrication simulation of O-ring and U-cup hydraulic seals. Proceedings of the Institution of Mechanical Engineers, Part J: Journal of Engineering Tribology, vol. 225, no. 7, p. 603-610, DOl:10.1177/1350650110397236.

[14] Wizner, M., Jakubiec, W., Starczak, M. (2011). Description of surface topography of sealing rings. Wear, vol. 271, no. 3-4, p. 571-575, D0I:10.1016/j.wear.2010.04.036.

[15] Yamabe, J., Koga, A., Nishimura, S. (2013). Failure behavior of rubber 0-ring under cyclic exposure to high-pressure hydrogen gas. Engineering Failure Analysis, vol. 35, p. 193-205, D0I:10.1016/j.engfailanal.2013.01.034.

[16] Woo, S.Y, Lee, Y.J, Choi, I.M, Kim, B.S, Shin, H.H. (2002). Effects of the 0-ring used for sealing in high-pressure balances on measurements of pressure. Measurement Science and Technology, vol. 13, no. 8, p. 1353-1358, Dol:10.1088/09570233/13/8/325.

[17] Nishimura, S. (2014). Fracture behaviour of ethylene propylene rubber for hydrogen gas sealing under high pressure hydrogen. International Polymer Science and Technology, vol. 41 , no. 6, p. 360-366.

[18] Lingerkar, K., Khonsari, M.M. (2010). On the effects of sliding velocity and operating pressure differential in rotary 0-ring seals. Proceedings of the Institution of Mechanical Engineers, Part J: Journal of Engineering Tribology, vol. 224, no. 7, p. 649-657, D0I:10.1243/13506501JET755.

[19] Handrasekaran, C. (2009). Rubber Seals for Fluid and Hydraulic Systems. William Andrew, Norwich. 